\title{
H4K5 histone acetylation of $B R G 1$ is associated with heroin administration rather than addiction
}

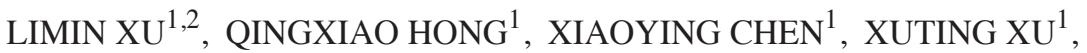 \\ HUIFEN LIU ${ }^{3,4}$, WENHUA ZHOU ${ }^{1,3,4}$ and SHIWEI DUAN ${ }^{1}$
}

\author{
${ }^{1}$ Zhejiang Provincial Key Laboratory of Pathophysiology, Ningbo University School of Medicine, Ningbo, Zhejiang 315211; \\ ${ }^{2}$ Huzhou Key Laboratory of Molecular Medicine, Huzhou Central Hospital, Huzhou, Zhejiang 313000; \\ ${ }^{3}$ Laboratory of Behavioral Neuroscience, Ningbo University; \\ ${ }^{4}$ Ningbo Institute of Microcirculation and Henbane, Ningbo, Zhejiang 315010, P.R. China
}

Received April 13, 2015; Accepted May 19, 2016

\section{DOI: $10.3892 / \mathrm{etm} .2016 .3517$}

\begin{abstract}
Diacetylmorphine hydrochloride (heroin) addiction is a chronic relapsing brain disorder that is a heavy public health burden worldwide. Brm/SWI2-related gene-1 (BRG1) is a tumor suppressor gene that can influence embryogenesis and the development of the cerebellum. The current study aimed to investigate the effect of histone $\mathrm{H} 4$ lysine 5 (H4K5) modifications on the BRGl gene in brain tissue of the ventral tegmental area (VTA) of heroin-addicted rats. A total of 21 male Sprague Dawley rats were raised in a standard manner and underwent heroin self-administration training. Rats were randomly divided into three equal groups: Group A, self-administered delivery of heroin; group B, yoked delivery of heroin; and group C, yoked delivery of saline. The VTA was harvested and subjected to chromatin immunoprecipitation (ChIP) analysis. Gene expression was evaluated by quantitative polymerase chain reaction. We calculated the recovery rate, which indicated the percentage of the total input $B R G I$ recovered by ChIP. Our results showed that $B R G I$ was less associated with H4K5 histone modification in the group of rats that underwent heroin self-administration than in the other two groups (A vs. $\mathrm{B}, \mathrm{P}=0.031$; A vs. $\mathrm{C}, \mathrm{P}=0.067$ ). The recovery fold changes of the self-administration group and the passive-administration group were significantly different from those of the group with yoked saline (A vs. $\mathrm{C}, \mathrm{P}=0.013$; $\mathrm{B}$ vs. $\mathrm{C}, \mathrm{P}=0.009$; $\mathrm{A}$ vs. $\mathrm{B}, \mathrm{P}=0.731$ ). The results of the current study demonstrated that $\mathrm{H} 4 \mathrm{~K} 5$ histone acetylation of $B R G 1$ in the VTA may be associated with heroin administration, but not addiction.
\end{abstract}

Correspondence to: Dr Shiwei Duan or Dr Wenhua Zhou, Zhejiang Provincial Key Laboratory of Pathophysiology, Ningbo University School of Medicine, 818 Fenghua Road, Ningbo, Zhejiang 315211, P.R. China

E-mail: duanshiwei@nbu.edu.cn

E-mail:whzhou@vip.163.com

Key words: heroin addiction, histone acetylation, ventral tegmental area, chromatin immunoprecipitation

\section{Introduction}

Diacetylmorphine hydrochloride (heroin) addiction is a chronic relapsing brain disease that is characterized by compulsive drug seeking, drug abuse and high drug tolerance (1). Heroin abuse is regarded as a huge burden on the public health and economy of China (2). Long-term use of heroin can damage the brain (3), lung (4) and liver (5), and compromise normal immune function $(6,7)$. It has previously been demonstrated that comorbidity with heroin abuse is one of the reasons for the rapid spread of infectious diseases such as HIV/AIDS (8) and hepatitis $(5,9)$.

Heroin alters the brain's reward system and enhances the demand for the reward in addicts (10). Heroin has been demonstrated to have a central role in the reward system, drug cravings and relapse (11). An important component of heroin reward is the ventral tegmental area (VTA), which is associated with dopamine (12), emotion (13), memory (14) and drug dependency (15). Various addiction-associated genes have been investigated with the aim of elucidating the association between polymorphisms and addiction, including dopamine beta-hydroxylase (16), dopamine receptor D2 $(17,18)$, dopamine receptor D4 $(18,19)$ and catechol-O-methyltransferase (20). Tsuang et al (21) compared drug abuse among 3372 pairs of twins and demonstrated a genetic predisposition to heroin addiction. The interaction between environmental and genetic factors, which is regarded as epigenetic modification, has previously been found in cases of chronic drug abuse and relapse (22). Notably, there are substantial differences in the influence of heroin among individuals, particularly in the treatment of heroin addiction (23).

$\mathrm{Brm} / \mathrm{SWI}$ 2-related gene-1 (BRG1) gene, which is also known as SWI/SNF-related, matrix associated, actin dependent regulator of chromatin (SMARC)A4, is an ATP-dependent chromatin-remodeling enzyme that recognizes acetylated histone H4 lysine 8 (H4K8) (24). Increased H4K8 acetylation results in increased repressor element 1-silencing transcription-factor recruitment $(24,25)$. Histone acetylation has been shown to promote transcriptional activity (26). BRGl is a tumor suppressor gene in the SMARC family that is crucially involved in the formation of malignant rhabdoid tumors, and the loss of SMARC proteins can impair the development of the cerebellum (27). BRG1 attenuation promotes non-small 
cell lung cancer aggressiveness by altering nucleosome positioning (28). Other findings have indicated that SMARCA4 promotes a dual active/repressive function at distal regulatory sequences and has an important role in tissue-specific gene regulation during embryogenesis (29). A comparison of the prefrontal cortex from amyloid precursor protein wild type $(\mathrm{APP}+/+)$ and knockout mice (APP-/-) indicated that the acetylation of $\mathrm{H} 4 \mathrm{~K} 5$ was enriched by the early growth response (EGRl) promoter in APP-/- mice, with EGRl known to be an immediate early gene involved in memory formation (30).

In light of these previous findings, the aim of the present study was to elucidate the association between addiction and histone acetylation of H4K5 with BRG1.

\section{Materials and methods}

Animals and groupings. A total of 21 male Sprague Dawley rats 13.91+1.34 weeks old and weighing 250-300 g, were obtained from the Experimental Animal Center of Zhejiang Province. The rats were subsequently housed in a temperature $\left(22-24^{\circ} \mathrm{C}\right)$ - and humidity (40-50\%)-controlled room with a reversed 12-h light-dark cycle (lights on 7:00 p.m.-7:00 a.m.) with ad libitum access to food and water. Trainings were performed between 9:00 a.m. and 5:00 p.m. Rats were randomly divided into three equal groups $(n=7)$ : Group A, self-administered delivery of heroin; group B, yoked delivery of heroin; and group C, yoked delivery of saline. All animal procedures were conducted in accordance with the National Institutes of Health Guide for the Care and Use of Laboratory Animals.

Surgical procedure. Rats were implanted with chronically indwelling intravenous catheters under sodium pentobarbital (50 mg/kg, i.m; Sigma-Aldrich, St. Louis, MO, USA) anesthesia. A silicon catheter (length, $4 \mathrm{~cm}$; inner diameter, $0.51 \mathrm{~mm}$; outer diameter, $0.94 \mathrm{~mm}$ ) was subsequently inserted into the right external jugular vein and secured with thread. The other end of the catheter (length, $10 \mathrm{~cm}$; PE20) exited the rats from an incision on the back of the body. Catheters were flushed daily with $0.3 \mathrm{ml}$ benzylpenicillin (200,000 units) and $0.3 \mathrm{ml}$ heparin $(50 \mathrm{U} / \mathrm{ml})$ to prevent bacterial infection and maintain catheter patency, and were capped daily. Rats were allowed to recover for at least 7 days.

Heroin administration. Heroin was obtained from the National Institute of Forensic Science of China (Shanghai, China). A total of 21 custom-made Plexiglas operant boxes (working area, 30x30x30 cm) were used. Each operant box was equipped with two nose-pokes, with an LED light and an infrared probe inside each. Heroin self-administration sessions were conducted daily for 21 consecutive days under a fixed ratio 1 (FR1) schedule. In brief, rats were moved to the operant chambers, and their connectors were attached to the infusion lines. Each trial began with illumination of the house-light. Rats received a single heroin infusion at a dose of $0.05 \mathrm{mg} / \mathrm{kg} /$ infusion paired with a 2 -sec active nose-poke light, following completion of the ratio requirement in the active nose-poke. The house-light was turned off during heroin infusions. A 20-sec inter-trial interval followed, after which another trial began. Responding in the inactive nose-poke period had no consequences. The session ended after $4 \mathrm{~h}$ or 50 heroin infusions, whichever occurred first. Rats were returned to their individual cages shortly after the session.

The remaining two groups served as the yoked heroin and yoked saline controls. Yoked heroin rats received amounts of heroin equal to those of the rats in the self-administration group over the same time course; however, their exposure to heroin was not explicitly associated with nose-poke responses. Yoked saline control rats received the same volume of saline at the same frequency over a 4-h period. Rats were deeply anaesthetized with sodium pentobarbital ( $80 \mathrm{mg} / \mathrm{kg}$ intraperitoneally) and decapitated after the final behavioral training session. The VTA was isolated using a rat brain matrix. The entire VTA was removed from the decapitated rats, immediately flash frozen in liquid nitrogen, and subsequently stored at $-80^{\circ} \mathrm{C}$ until further use.

Chromatin immunoprecipitation (ChIP) assay. ChIP assays were performed using standard procedures $(31,32)$. Frozen VTA tissue was pulverized into a powder using a hammer and liquid nitrogen. A total of $60 \mathrm{mg}$ VTA tissue was prepared for each group of 7 rats. The tissue was cross-linked in formaldehyde at a final concentration of $0.7 \%$. All experimental reagents were included in the Magna ChIP-Seq ${ }^{\mathrm{TM}}$ kit (17-1010, EMD Millipore, Billerica, MA, USA). Sonication was conducted using a Bioruptor UCD-200 (Diagenode, Liège, Belgium) under the optimal conditions to shear cross-linked DNA to fragments of 100-600 base pairs in length. In brief, chromatin samples were sheared for 5, 3, 3, 3 and 2 cycles of $30 \mathrm{sec}$ on/ $30 \mathrm{sec}$ off for a total of 16 cycles and paused for $1 \mathrm{~min}$ with a short centrifugation during the intervals. Equal amounts of chromatin lysate $(50 \mu \mathrm{l})$ were diluted with ChIP buffer $\mathrm{H}$ (Auto Histone ChIP-seq kit; C01010022; Diagenode) to a final volume of $200 \mu \mathrm{l}$, ensuring that the final concentration of SDS was $<1 \%$. An aliquot $(1 \% ; 2 \mu \mathrm{l})$ of the pre-immunoprecipitated lysate was saved as 'input' for subsequent normalization. A SX-8 G IP-Star ${ }^{\circledR}$ automated system (Diagenode) was used for the immunoprecipitation reaction, with H4K5 (9672S; Cell Signaling Technology, Inc.) as the target antibody and normal rabbit IgG as a negative control, due to the rabbit source of the antibody. The DNA, associated with acetylated histones, was extracted using a Diagenode Auto IPure kit (C03010010; Diagenode), and subsequently resuspended in $50 \mu \mathrm{l}$ buffer $\mathrm{C}$ from the kit.

The level of specific histone modification at the gene of interest was determined by measuring the amount of acetylated histone-associated DNA by quantitative polymerase chain reaction (qPCR) using a LightCycler ${ }^{\circledR} 480$ (Roche Diagnostics, Mannheim, Germany). To avoid errors that may occur from differences in the loading quantity of the samples, GAPDH was taken as the internal reference for $\mathrm{qPCR}$. The $\mathrm{qPCR}$ reaction was performed in a total volume of $10 \mu \mathrm{l}$ and contained $5 \mu \mathrm{l}$ of $2 \mathrm{X}$ SYBR Green Master Mix, $0.2 \mu \mathrm{l}$ primers (from a stock at $10 \mu \mathrm{M}$ each), $1.8 \mu \mathrm{l}$ of $\mathrm{ddH}_{2} \mathrm{O}$ and $3 \mu \mathrm{l}$ of ChIP or input sample. Triplicate qPCR reactions per ChIP sample were performed. The primers used were as follows: BRG1, forward 5'-ACAGAG CCTTGCAGAGCA-3' and reverse 5'- GAGGAAAGTGAA GCCGAGA-3'; GAPDH, forward 5'-CGTAGCTCAGGCCTC TGCGCCCTT-3' and reverse 5'-CTGGCACTGCACAAGAAG ATGCGGCTG-3'. qPCR conditions included a pre-incubation stage at $95^{\circ} \mathrm{C}$ for $3 \mathrm{~min}$, followed by 40 cycles at $95^{\circ} \mathrm{C}$ for $30 \mathrm{sec}$, $60^{\circ} \mathrm{C}$ for $30 \mathrm{sec}$ and primer extension at $72^{\circ} \mathrm{C}$ for $30 \mathrm{sec}$, then a 


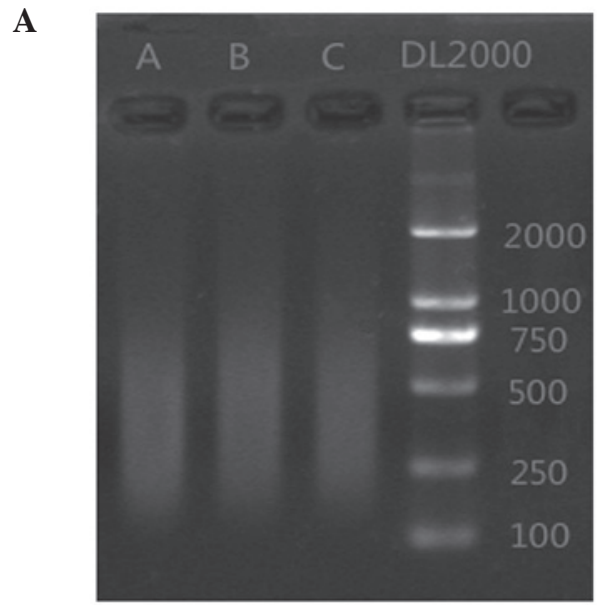

B

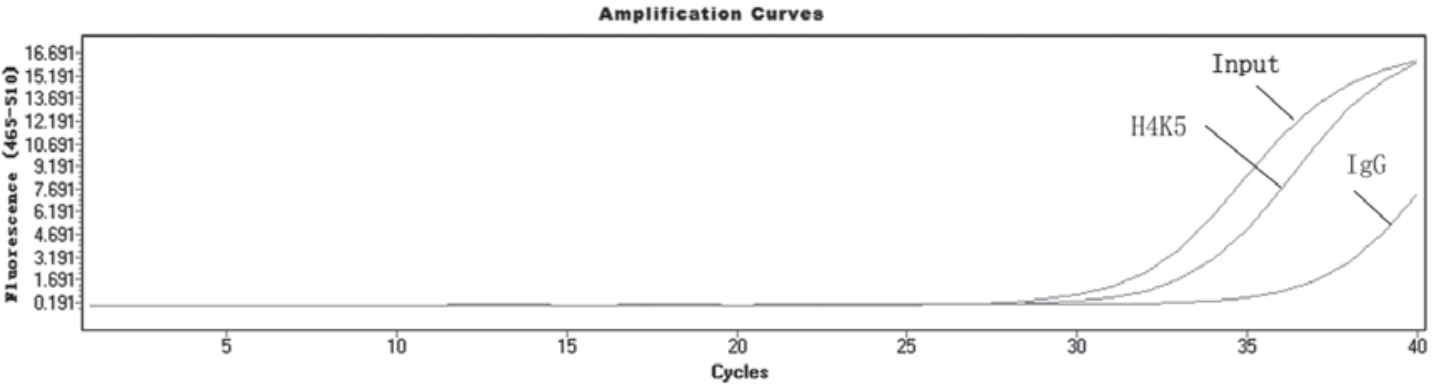

Figure 1. DNA fragmentation and quantitative polymerase chain reaction amplification. (A) DNA fragment size, as determined by electrophoresis after sonication. (B) Amplification curves of the samples with different antibodies. A, self-administered delivery of heroin; B, yoked delivery of heroin; C, yoked delivery of saline.

melting curve $\left(90^{\circ} \mathrm{C}\right.$ for $10 \mathrm{sec}, 60^{\circ} \mathrm{C}$ for $30 \mathrm{sec}$ and $\left.90^{\circ} \mathrm{C} 10 \mathrm{sec}\right)$ with final cooling at $40^{\circ} \mathrm{C}$ for $30 \mathrm{sec}$. The results of qPCR for enrichment were performed using a relative standard curve method to compare DNA from a mock IP using IgG versus DNA immunoprecipitated with the ChIP antibody.

Data analysis. The recovery rate was calculated by referring to the Auto Histone ChIP-seq kit (Diagenode, Belgium) and the manufacturer's instructions as recovery rate \% $(\mathrm{ChIP} /$ total input $)=2^{\wedge}[(\mathrm{Ct}(\mathrm{x} \%$ input $)-\log (\mathrm{x} \%) / \log 2)-\mathrm{Ct}(\mathrm{ChIP})] \times 100 \%$. Fold enrichment over IgG was calculated by the recovery of BRG1/GAPDH. Ct (ChIP) and Ct (x\% input) are threshold values obtained from the exponential phase of qPCR for the IP'd DNA and input sample, respectively. The compensatory factor $[\log (x \%) / \log 2]$ is used to take into account the dilution, 1:x, of the input. The recovery is the \% (ChIP/total input). Comparisons among the three groups or between two groups were calculated by one-way analysis of variance and Student's t-test using SPSS 16.0 (SPSS, Inc., Chicago, IL, USA). P<0.05 was considered to indicate a statistically significant difference.

\section{Results}

Quality control of ChIP assay. The association between histone acetylation and heroin addiction was evaluated in three groups of rats. Group A contained rats that received heroin by self-administration, whereas the rats of group B and group C were administered heroin and saline, respectively, in a yoked passive manner.

VTA tissue was cross-linked with $0.7 \%$ formaldehyde, and the DNA-histone complex was sheared to fragments of
100-600 bp in length via sonication (Fig. 1A). ChIP assays were then performed using an antibody against H4K5, and the amount of DNA associated with the modified histone was quantified using qPCR. The results demonstrated that the IgG was not amplified by qPCR, which indicated that the experimental system was reliable. Example curves for qPCR are presented in Fig. 1B. The results of quality control showed that the experimental results meet the requirements.

Comparison of recovery rate. Recovery was calculated, which indicated the percentage of the total input BRGl that was recovered by ChIP. The results demonstrated that the quantity of BRG1 combined with H4K5 modification differed among the three groups; however, recovery was consistently low $(0.52 \%, 0.78 \%$, and $0.74 \%$ for groups $\mathrm{A}, \mathrm{B}$ and $\mathrm{C}$ respectively; Fig. 2A) and the P-value was 0.063. Notably, a significant difference was detected between the rats that received heroin by self-administration and those that received heroin in a passive manner (A and $\mathrm{B}, \mathrm{P}=0.031$; Fig. 2A). BRG1 was less associated with H4K5 histone modification in the heroin self-administration group, as compared with the other two groups ( $\mathrm{A}$ and $\mathrm{B}, \mathrm{P}=0.031$; $\mathrm{A}$ and $\mathrm{C}, \mathrm{P}=0.067$ ). No other significant differences were detected between the passive heroin groups and the saline-administered group ( $\mathrm{P}=0.760)$ (1).The results of the recovery rate suggested that the group of heroin self-administration had less H4K5 associated with BRG1.

Comparison of fold enrichment. To avoid the errors that occurred by differences in the quantity of the samples loaded, GAPDH was taken as the internal reference for qPCR. Fold enrichment indicated the ratio of $B R G 1: G A P D H$ was associated 

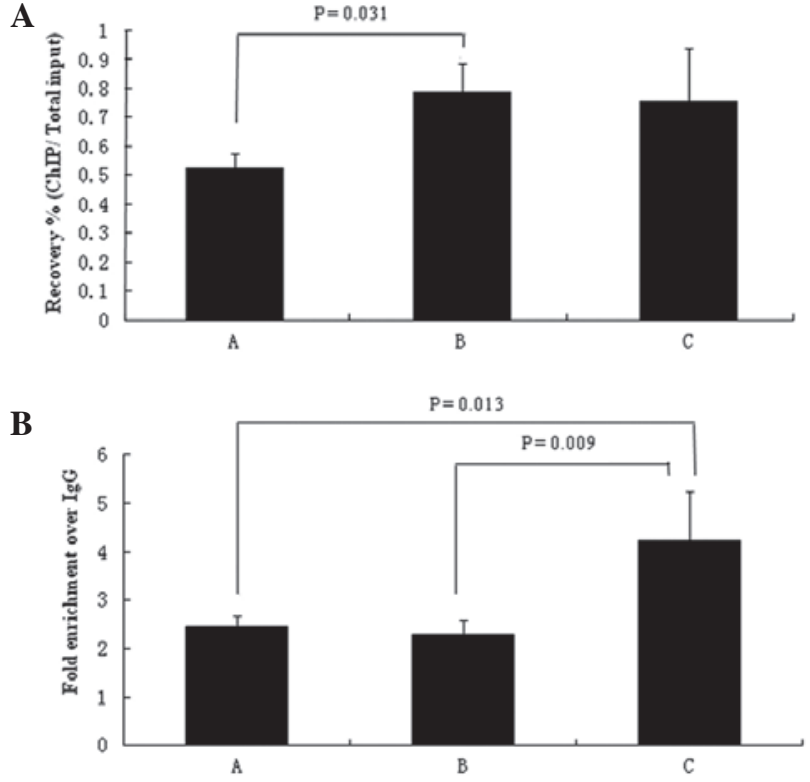

Figure 2. (A) Recovery rate of H4K5 acetylation-associated DNA input and (B) fold enrichment over IgG of H4K5 acetylation-associated DNA. Recovery rate was calculated as recovery rate $\%(\mathrm{ChIP} /$ total input $)=2^{\wedge}[(\mathrm{Ct}$ ( $\mathrm{x} \%$ input $\left.)-\log (\mathrm{x} \%) / \log 2)-\mathrm{Ct}(\mathrm{ChIP})\right] \mathrm{x} 100 \%$. Fold enrichment over $\mathrm{IgG}$ was calculated by the recovery of the target gene/GAPDH. A, self-administered delivery of heroin; B, yoked delivery of heroin; $\mathrm{C}$, yoked delivery of saline. H4K5, histone H4 lysine 5; ChIP, chromatin immunoprecipitation.

with H4K5 histone modification. The results demonstrated that the heroin-treated rats exhibited lower fold changes than those receiving saline $(2.44,2.28,4.16$ for groups $\mathrm{A}, \mathrm{B}$ and $\mathrm{C}$ respectively; Fig. 2B). Furthermore, there was a significant difference among the three groups $(\mathrm{P}=0.019)$, specifically between group $\mathrm{C}$ and the other two groups (A vs. $\mathrm{C}, \mathrm{P}=0.013$; $\mathrm{B}$ vs. $\mathrm{C}, \mathrm{P}=0.009$; and $\mathrm{A}$ vs. $\mathrm{B}, \mathrm{P}=0.731$; Fig. $2 \mathrm{~B}$ ). The fold enrichments demonstrated that $\mathrm{H} 4 \mathrm{~K} 5$ histone acetylation of $B R G 1$ in the VTA may be associated with heroin administration but not associated with the intake methods.

\section{Discussion}

Drug addiction is regarded as a huge burden on society (2). Addiction is characterized by compulsive excessive drug intake and relatively low control over limiting the intake (33). The reward system in the brain is activated by heroin intake and dopamine is released from the VTA to the nucleus accumbens, which subsequently induces the acute reward effect and negative reinforcement of opioids (33). Extended durations of repeated stimulation result in a decrease of the demand for natural rewards, and an increase in the seeking out and self-administration of drugs (14).

VTA, which is a component of the brain's mesolimbic dopamine system, is an important pathway for the reward circuit $(14,34)$, and is closely associated with addiction and reward effects (14). Dopamine receptor stimulation is critical for heroin-conditioned immunomodulation, whereas only the anterior part of he VTA has been demonstrated to haves a role in immunomodulation (7).

Chromatin modifications is one of the major epigenetic pathways known to modify gene expression. Modifications, such as acetylation, methylation and phosphorylation of chromatin histone aminoterminal tails, can be markers of transcriptional regulation (22). Histone acetylation is associated with the activation of chromatin structure, which promotes transcriptional activity (26). Binding of the Sp1 transcription factor and the BRG1 and BAF155 chromatin remodeling factors to the promoter induces the activation of opoid receptor (OPR)M1 $(35,36)$, which is the target of the bioactive products of heroin (6-monoacetylmorphine and morphine) (37). Notably, increased OPRM1 promoter methylation and histone deacetylation is associated with OPRMI gene silencing (38).

Although the current study was unable to detect an association between $B R G 1$ epigenetic modifications and heroin addiction, the present findings indicated a link between addiction and histone modification. Long-term exposure to nicotine has been shown to stimulate the acetylation of both histones $\mathrm{H} 3$ and $\mathrm{H} 4$ at the $F o s B$ promoter and reduced histone deacetylase activity (39). Furthermore, in a previous study, acute cocaine exposure increased $\mathrm{H} 4$ acetylation at the c-Fos promoter, whereas chronic cocaine exposure induced increased $\mathrm{H} 3$ acetylation at the brain derived neutrophic factor $(B D N F)$ and cyclin dependent kinase 5 gene promoters in mouse striatum (40). $B D N F$ expression was increased by either acute or chronic cocaine treatment and by withdrawal in the rat nucleus accumbens shell, whereas it increased only following withdrawal in the hippocampus (41). BDNF expression continued to increase after withdrawal, which implies a long-lasting epigenetic response to addiction (42).

The present study had several limitations. Firstly, although the rats were divided into three groups according to heroin exposure and administration type, the study design may still be too simple to explain the complex trait of heroin addiction. Secondly, the influence of heroin on H4K5 acetylation was only investigated in VTA tissues. Other tissues associated with addiction, such as the habenula nucleus, nucleus accumbens, hippocampus, and pallium, represent potential targets for future study. Thirdly, only the BRGl gene was investigated in the present study, and additional relevant genes may be discovered by deep sequencing. In addition, minimal VTA tissue was harvested from each rat, leading to difficulties in the ChIP experiments. The combination of tissues in the respective groups contributes to the success of the experiment, but decreases the individual differences detected.

In conclusion, the results of the present study indicated that $B R G 1$-associated $\mathrm{H} 4 \mathrm{~K} 5$ histone modification was related to heroin administration rather than addiction. Future investigation into the function of this epigenetic modification after heroin administration is required.

\section{Acknowledgements}

The present study was supported by the National Basic Research Program of China (grant no. 2015CB553504), the Nature Science Foundation of China (grant nos. U1132602, 81171257, 31100919 and 81371469), the Natural Science Foundation of Zhejiang Province (grant nos. LR13H020003 and LY14H310002), and the K.C. Wong Magna Fund in Ningbo University (grant no. 2012C50032) and Ningbo Social Development (grant no. 2013C50033) research projects. 


\section{References}

1. Levran O, Londono D, O'Hara K, Nielsen DA, Peles E, Rotrosen J, Casadonte P, Linzy S, Randesi M, Ott J, et al: Genetic susceptibility to heroin addiction: A candidate gene association study. Genes Brain Behav 7: 720-729, 2008.

2. Sun HQ, Bao YP, Zhou SJ, Meng SQ and Lu L: The new pattern of drug abuse in China. Curr Opin Psychiatry 27: 251-255, 2014.

3. Wang X, Zhou X, Liao Y, Tang J, Liu T and Hao W: Brain function of heroin addicts after withdrawal. Zhong Nan Da Xue Xue Bao Yi Xue Ban 36: 733-738, 2011.

4. Prowse SJ, Lima T, Irion KL, Burhan H, Hochhegger B and Marchiori E: Valsalva manoeuvre effect on distribution of lung damage in heroin inhalation. Br J Radiol 84: e200-e201, 2011.

5. Vandelli C, Piaggi V, Battilani R, Cariani E and Sirotti MA Relationship between HBV markers and heroin as a cause of liver injury in drug addicts. Drug Alcohol Depend 14: 129-133, 1984.

6. Szczytkowski JL, Fuchs RA and Lysle DT: Ventral tegmental area-basolateral amygdala-nucleus accumbens shell neurocircuitry controls the expression of heroin-conditioned immunomodulation. J Neuroimmunol 237: 47-56, 2011.

7. Hutson LW, Szczytkowski JL, Saurer TB, Lebonville C, Fuchs RA and Lysle DT: Region-specific contribution of the ventral tegmental area to heroin-induced conditioned immunomodulation. Brain Behav Immun 38: 118-124, 2014.

8. Broz D, Wejnert C, Pham HT, DiNenno E, Heffelfinger JD Cribbin M, Krishna N, Teshale EH and Paz-Bailey G; National HIV Behavioral Surveillance System Study Group: HIV infection and risk, prevention and testing behaviors among injecting drug users-National HIV behavioral surveillance system, 20 US cities, 2009. MMWR Surveill Summ 63: 1-51, 2014.

9. Roux P, Fugon L, Jones JD and Comer SD: Hepatitis C infection in non-treatment-seeking heroin users: The burden of cocaine injection. Am J Addict 22: 613-618, 2013

10. Hutcheson DM, Everitt BJ, Robbins TW and Dickinson A: The role of withdrawal in heroin addiction: Enhances reward or promotes avoidance? Nat Neurosci 4: 943-947, 2001.

11. Koob G and Kreek MJ: Stress, dysregulation of drug reward pathways and the transition to drug dependence. Am J Psychiatry 164: 1149-1159, 2007.

12. Ranaldi R: Dopamine and reward seeking: The role of ventral tegmental area. Rev Neurosci 25: 621-630, 2014.

13. Meye FJ and Adan RA: Feelings about food: The ventral tegmental area in food reward and emotional eating. Trends Pharmacol Sci 35: 31-40, 2014

14. Volman SF, Lammel S, Margolis EB, Kim Y, Richard JM, Roitman MF and Lobo MK: New insights into the specificity and plasticity of reward and aversion encoding in the mesolimbic system. J Neurosci 33: 17569-17576, 2013.

15. Vargas-Perez H, Bahi A, Bufalino MR, Ting-A-Kee R, Maal-Bared G, Lam J, Fahmy A, Clarke L, Blanchard JK, Larsen BR, et al: BDNF signaling in the VTA links the drug-dependent state to drug withdrawal aversions. J Neurosci 34: 7899-7909, 2014.

16. Xie X, Xu L, Liu H, Chen W, Zhuang D, Zhang J, Duan S and Zhou W: Positive association between-1021TT genotype of dopamine beta hydroxylase gene and progressive behavior of injection heroin users. Neurosci Lett 541: 258-262, 2013.

17. Nelson EC, Heath AC, Lynskey MT, Agrawal A, Henders AK, Bowdler LM, Todorov AA, Madden PA, Moore E, Degenhardt L, et al: PTSD risk associated with a functional DRD2 polymorphism in heroin-dependent cases and controls is limited to amphetamine-dependent individuals. Addict Biol 19: 700-707, 2014

18. Vereczkei A, Demetrovics Z, Szekely A, Sarkozy P, Antal P, Szilagyi A, Sasvari-Szekely $M$ and Barta C: Multivariate analysis of dopaminergic gene variants as risk factors of heroin dependence. PloS One 8: e66592, 2013

19. Lai JH, Zhu YS, Huo ZH, Sun RF, Yu B, Wang YP, Chai ZQ and Li SB: Association study of polymorphisms in the promoter region of DRD4 with schizophrenia, depression and heroin addiction. Brain Res 1359: 227-232, 2010.

20. Kibitov AO, Voskoboeva Elu, Brodianskiǔ VM, Chuprova NA and Smirnova EV: Association study of the Val158Met polymorphism of the catechol-O-methyltransferase gene and alcoholism and heroin dependence: the role of a family history. Zh Nevrol Psikhiatr Im S S Korsakova 110: 84-88, 2010.

21. Tsuang MT, Lyons MJ, Eisen SA, Goldberg J, True W, Lin N, Meyer JM, Toomey R, Faraone SV and Eaves L: Genetic influences on DSM-III-R drug abuse and dependence: A study of 3,372 twin pairs. Am J Med Genet 67: 473-477, 1996.
22. Nielsen DA, Utrankar A, Reyes JA, Simons DD and Kosten TR: Epigenetics of drug abuse: Predisposition or response. Pharmacogenomics 13: 1149-1160, 2012.

23. Kreek MJ, Nielsen DA, Butelman ER and LaForge KS: Genetic influences on impulsivity, risk taking, stress responsivity and vulnerability to drug abuse and addiction. Nature Neurosci 8 1450-1457, 2005

24. Ooi L, Belyaev ND, Miyake K, Wood IC and Buckley NJ: BRG1 chromatin remodeling activity is required for efficient chromatin binding by repressor element 1-silencing transcription factor (REST) and facilitates REST-mediated repression. J Biol Chem 281: 38974-38980, 2006.

25. Ooi L and Wood IC: Chromatin crosstalk in development and disease: Lessons from REST. Nat Rev Genet 8: 544-554, 2007.

26. McQuown SC and Wood MA: Epigenetic regulation in substance use disorders. Current Psychiatry Rep 12: 145-153, 2010.

27. Moreno N, Schmidt C, Ahlfeld J, Pöschl J, Dittmar S, Pfister SM, Kool M, Kerl K and Schüller U: Loss of Smarc proteins impairs cerebellar development. J Neurosci 34: 13486-13491, 2014.

28. Orvis T, Hepperla A, Walter V, Song S, Simon J, Parker J, Wilkerson MD, Desai N, Major MB, Hayes DN, et al: BRG1/SMARCA4 inactivation promotes non-small cell lung cancer aggressiveness by altering chromatin organization. Cancer Res 74: 6486-6498, 2014.

29. Attanasio C, Nord AS, Zhu Y, Blow MJ, Biddie SC, Mendenhall EM, Dixon J, Wright C, Hosseini R, Akiyama JA, et al: Tissue-specific SMARCA4 binding at active and repressed regulatory elements during embryogenesis. Genome Res 24: 920-929, 2014

30. Hendrickx A, Pierrot N, Tasiaux B, Schakman O, Kienlen-Campard P, De Smet C and Octave JN: Epigenetic regulations of immediate early genes expression involved in memory formation by the amyloid precursor protein of Alzheimer disease. PloS One 9: e99467, 2014

31. Haring M, Offermann S, Danker T, Horst I, Peterhansel C and Stam M: Chromatin immunoprecipitation: Optimization, quantitative analysis and data normalization. Plant Methods 3: 11, 2007.

32. Murgatroyd C, Hoffmann A and Spengler D: In vivo ChIP for the analysis of microdissected tissue samples. Methods Mol Biol 809: 135-148, 2012

33. Koob GF and Le Moal M: Drug addiction, dysregulation of reward and allostasis. Neuropsychopharmacology 24: 97-129, 2001.

34. Bromberg-Martin ES, Matsumoto M and Hikosaka O: Dopamine in motivational control: Rewarding, aversive and alerting. Neuron 68: 815-834, 2010.

35. Hwang CK, Kim CS, Kim do K, Law PY, Wei LN and Loh HH: Up-regulation of the mu-opioid receptor gene is mediated through chromatin remodeling and transcriptional factors in differentiated neuronal cells. Mol Pharmacol 78: 58-68, 2010

36. Hwang CK, Song KY, Kim CS, Choi HS, Guo XH, Law PY, Wei LN and Loh HH: Epigenetic programming of mu-opioid receptor gene in mouse brain is regulated by $\mathrm{MeCP} 2$ and $\mathrm{Brg} 1$ chromatin remodelling factor. J Cell Mol Med 13: 3591-3615, 2009

37. Kreek MJ, Bart G, Lilly C, LaForge KS and Nielsen DA: Pharmacogenetics and human molecular genetics of opiate and cocaine addictions and their treatments. Pharmacol Rev 57: $1-26,2005$.

38. Hwang CK, Song KY, Kim CS, Choi HS, Guo XH, Law PY, Wei LN and Loh HH: Evidence of endogenous mu opioid receptor regulation by epigenetic control of the promoters. Mol Cell Biol 27: 4720-4736, 2007.

39. Levine A, Huang Y, Drisaldi B, Griffin EA Jr, Pollak DD, Xu S, Yin D, Schaffran C, Kandel DB and Kandel ER: Molecular mechanism for a gateway drug: Epigenetic changes initiated by nicotine prime gene expression by cocaine. Sci Transl Med 3: 107ra109, 2011

40. Kumar A, Choi KH, Renthal W, Tsankova NM, Theobald DE, Truong HT, Russo SJ, Laplant Q, Sasaki TS, Whistler KN, et al: Chromatin remodeling is a key mechanism underlying cocaine-induced plasticity in striatum. Neuron 48: 303-314, 2005.

41. Filip M, Faron-Górecka A, Kuśmider M, Gołda A, Frankowska M and Dziedzicka-Wasylewska M: Alterations in BDNF and trkB mRNAs following acute or sensitizing cocaine treatments and withdrawal. Brain Res 1071: 218-225, 2006.

42. Grimm JW, Lu L, Hayashi T, Hope BT, Su TP and Shaham Y: Time-dependent increases in brain-derived neurotrophic factor protein levels within the mesolimbic dopamine system after withdrawal from cocaine: Implications for incubation of cocaine craving. J Neurosci 23: 742-747, 2003. 